\title{
Da mestiçagem à reconstrução diaspórica do pertencimento étnico-racial
}

\author{
From Miscegenation to the diasporic reconstruction of \\ the ethnic-racial belonging
}

Priscila Martins Medeiros a Paulo Alberto dos Santos Vieirab

Resumo O artigo traz uma reflexão a respeito das mudanças conceituais percebidas no Brasil ao longo do último século no que tange às suas características étnico-raciais. O objetivo é analisar as transformações sentidas não apenas na composição étnicoracial do país, mas também os motivos sociais, teóricos e políticos que fizeram com que se abandonassem os debates em torno do mestiço e se chegasse ao contexto atual, em que se pauta outra lógica, qual seja: a identificação afro-brasileira. A ideia de um país mestiço e a busca pelo branqueamento do país significaram a institucionalização da desmemória das origens étnico-raciais. Isso fez com que negros e indígenas fossem incorporados na sociedade brasileira não como sujeitos plenos de direitos, mas enquanto "marcos da brasilidade". O negro no Brasil do século XXI, por meio de sua intelectualidade, tem se afirmado enquanto afro-brasileiro, trilhando o caminho de recriar sua origem para além da fronteira nacional; ou seja, não se trata de um retorno ao lar africano, mas do refazer de sua subjetividade, em um terceiro espaço, um território subjetivo. Isso se dá por meio da crítica à racialização de sua pertença étnica, bem como à hierarquização a qual foi submetida sua história, denunciando a maneira como a diferença se transformou em pretexto e justificativa para a desigualdade social. Palavras-chave Afro-Brasileiro; Racialização; Identidade; Diáspora Negra.

Abstract The paper presents a reflection on the population and conceptual changes seen in Brazil over the last century in terms of their ethnic and racial characteristics. The purpose is to analyze the changes felt not only in the ethnic and racial composition of the country, but also the social, theoretical and political reasons that led to the dismissal of the debates around the mestizo and to the current context, guided into another identity logic: the African-Brazilian identification. The idea of a mixed country and the search for the country bleaching meant the institutionalization of

a Doutora em Sociologia e Professora do Departamento de Sociologia da Universidade Federal de São Carlos.

b Doutor em Sociologia e Professor do Programa de Pós-Graduação em Educação da Universidade do Estado de Mato Grosso. 
desmemória of ethnic and racial backgrounds. This meant that blacks and Indians were incorporated into Brazilian society not as subjects of rights but as "marks of Brazilianness". The black in Brazil in the twenty-first century, through the black intelligentsia, has been claimed as African-Brazilian, and has gone the way of recreating its origin beyond national borders. This is not a return to the African home, but the remake of his subjectivity, in a third space, a subjective territory made through the critique of the racialization of their ethnicity as well as the criticism of the hierarchization to which its history was submitted, denouncing how difference has become pretext and justification for social inequality.

Keywords African-Brazilian; Racialization; Identity; Black Diaspora.

\section{INTRODUÇÃO}

Há, no Brasil, uma frase bastante famosa e que representa bem os desafios colocados para quem objetiva analisar suas relações sociais: "o Brasil não é um país para iniciantes". De fato, em um país de profundas desigualdades sociais e com uma história de colonização que ainda deixa severas marcas, as relações sociais e, em especial, as relações étnico-raciais são mais complexas do que possamos imaginar em um primeiro momento.

Diferentemente do discurso construído sobre o país e divulgado pelo mundo afora, há um racismo latente e que ainda perpetua fortes desigualdades entre brancos, negros e indígenas. Durante a primeira metade do século XX, o Brasil ficou conhecido como "paraíso racial”, pois, supostamente, teria solucionado suas diferenças raciais. Diferentemente do que ocorreu nos Estados Unidos, por exemplo, aqui há uma população "mestiça" bastante evidente; isso, no entanto, não pode ser lido de maneira apressada enquanto resultado de um país onde exista respeito pelas diferenças étnicas e culturais. Muito pelo contrário, há um esforço por parte do Movimento Negro e de determinada intelectualidade de desmistificar a imagem de um Brasil cordial, na busca de uma melhor compreensão dos nossos dilemas raciais e na promoção de políticas públicas de reparação e reconhecimento.

O "mito da democracia racial", como ficou conhecido o discurso falacioso de que seríamos um oásis de respeito inter-racial, é uma construção cultural cujo

1 A democracia racial é o termo frequentemente utilizado no Brasil para defini-lo como país que, supostamente, soube liquidar o racismo. Tal ideário influenciou diretamente a literatura, a imprensa, as políticas e o próprio cotidiano do país durante quase todo o século XX, não estando fundamentado exclusivamente nas obras de Gilberto Freyre, mas tendo nelas suas principais inspirações. De acordo com Guimarães, a terminologia passou a ser utilizada na literatura acadêmica pela primeira vez através de Charles Wagley, em 1952, apesar de existirem registros sobre 
surgimento data das primeiras décadas do século XX, especialmente a partir do Estado Novo (1937-1945), e que vigorou até o final da ditadura militar (1964-1985). O mito se materializou nas relações políticas, econômicas e sociais como um todo, além de ter sido utilizado como mecanismo para limitar e dificultar as ações dos movimentos antirracistas (GUIMARÃES, 2001b, p.173-174).

O discurso mitológico da democracia racial age "lembrando" o/a negro/a que ele/a é uma pessoa negra, caso se esqueça disso em algum momento. É “aquela alteridade", que é ao mesmo tempo objeto de desejo e de escárnio (BнавнA, 2010, p.106), uma situação vacilante “entre o que está sempre 'no lugar', já conhecido, e algo que deve ser ansiosamente repetido" (BнAвнA, 2010, p.105). Ou, ainda, nas palavras de Frantz Fanon (2008, p.151), "há uma procura pelo negro, o negro é uma demanda, não se pode passar sem ele, ele é necessário, mas só depois de tornar-se palatável de uma determinada maneira”. Temos boas condições de colocar em tensão esse cenário de racismo se apostarmos no fortalecimento da educação para as relações étnico-raciais e de instrumentos legais, tais como a Lei 10.639/03, a Lei 11.645/o8 e outras modalidades de políticas públicas².

Frente a essa problemática, pretendemos apresentar a seguir uma análise a respeito das mudanças ocorridas no Brasil no que diz respeito à composição étnico-racial da população, como também as transformações conceituais que nos fizeram deslocar os debates em torno do "mestiço" para uma nova lógica, pautada na "afrodescendência", na crítica ao processo colonial e na reivindicação de uma identidade diaspórica.

\section{FUNDAMENTOS SOCIAIS E TEÓRICOS DO IDEÁRIO DA MESTIÇAGEM NO BRASIL}

Os estudos sobre as relações raciais no Brasil, desenvolvidos entre os anos 1870 e 1930, fazem parte de um projeto bastante conservador de descrição da realidade social a partir de explicações evolucionistas, que relacionavam "raça" ao meio ambiente - como pode ser observado na segunda parte (“O homem”) do livro Os Sertões, de Euclides da Cunha, publicado em 1902. Os termos dominantes durante o século XIX e também nas primeiras décadas do século seguinte foram marcados por discursos "biologizantes", digamos assim, que tentaram conferir

sua utilização por parte de Arthur Ramos e Roger Bastide, já durante os anos 1940 (GuimarãEs, 2002, p.139).

2 A Lei 10.639, aprovada em o9 de janeiro de 2003, torna obrigatório o ensino de história e cultura afro-brasileiras e africanas na educação básica pública e privada no Brasil. A Lei 11.645, de 10 de março de 2008, por sua vez, versa sobre a obrigatoriedade do ensino da história e cultura dos povos indígenas em toda a educação básica. 
status de inferioridade do negro frente aos europeus e euro-descendentes. Esse debate alicerçado na miscigenação variou de uma avaliação pessimista das possibilidades de se construir uma "nação" nos trópicos sobre tal base humana - e, nesta vertente, encontram-se, por exemplo, Nina Rodrigues e Euclides da Cunha -, até a perspectiva positiva de que a miscigenação levaria ao embranquecimento gradual da população - como defenderam Oliveira Viana, João Baptista Lacerda e Silvio Romero (Costa, 2002, p.40).

Nas noções mais tradicionais, defende-se que a formação e a estabilidade do Estado-Nação dependem da realização integral da equação: um território, um povo, uma língua. Isso se daria a partir da assimilação cultural, transformando a pluralidade racial, cultural e de valores civilizatórios em um grupo coeso de cidadãos (Munanga, 2006; Anderson, 1999; Moya \& Silvério, 2009). Miskolci (2012, p.21) realiza uma análise que aponta as duas últimas décadas do século XIX como sendo um período de gestão de ideais de progresso, embasados na defesa de uma "regeneração racial" mediante o embranquecimento da população, com o desejo de se inaugurar uma “civilização nos trópicos". De acordo com o autor, uma parcela considerável das interpretações históricas e sociológicas privilegiaram, ao descreverem esse momento, os temas da mudança do regime escravocrata para o trabalho livre e os reflexos políticos e econômicos desse processo. O que foi deixado em segundo plano nessas análises, de acordo com o mesmo autor, foi a formação de um novo imaginário social, pautado nos valores positivistas da ordem e do progresso.

$\mathrm{O}$ aspecto da ordem, de acordo com Miskolci, já foi amplamente debatido por meio das análises sobre a Proclamação da República e da construção de um distanciamento com relação à instabilidade política e à "anarquia”, frequentemente associados aos países latino-americanos da época. O que não foi realizado a contento, e o que motiva os estudos do autor, seria o aspecto do progresso, no qual, inegavelmente, o discurso nacionalista e do povo brasileiro aparecem em primeiro plano. O progresso guarda em si o ideal de uma civilização construída no futuro, mediante um processo político modernizante e uma "evolução humana"; mas, o grande obstáculo ao progresso no Brasil estaria, justamente, na composição étnico-racial de sua população (MiskolcI, 2012, p.22-23).

O Brasil, assim como outros países de experiência colonial, colaboraria para a emergência da modernidade, especialmente através de medidas sanitaristas e de reforma urbana, como a que aconteceu na cidade do Rio de Janeiro na primeira década do século XX. Então, se um dos aspectos centrais da modernidade é o "novo" enquanto valor, a "boa nova" como riqueza em comparação com o que se 
entende por estagnação dos períodos anteriores, esses elementos estavam todos revisitados no Brasil na passagem do século XIX para o XX. Isso se deu ancorado na desqualificação do povo brasileiro e em um cenário político de temores sobre uma possível revolta de escravizados. Não são raros os trabalhos que demonstraram que a abolição foi resultado de mais de quarenta anos de sérias crises do sistema escravista e de que, em maio de 1888, havia mais africanos e afro-brasileiros nos quilombos do que nas senzalas. A escravidão já demonstrava, há tempos, sinais de falência, de perda de legitimidade perante o cenário econômico internacional, da mesma forma que as revoltas negras no Brasil estavam saindo do controle do império. Dessa maneira, a construção discursiva em torno da princesa Isabel retirou por muito tempo o foco do protagonismo negro no processo de libertação da escravidão. Além disso, encobriu o aspecto de medo e de insegurança que se expressava nos discursos políticos da época: havia tanto um temor de que acontecesse uma grande revolta negra no país, nos moldes da Revolução Haitiana, quanto o medo de uma suposta "onda negra” que aconteceria no pós-abolição, que despejaria na sociedade "uma horda de homens semibárbaros, sem direção, sem alvo social” (AzEvedo, 2004, p.32-36).

O cenário de medos contra a população afro-brasileira já se apresentava em meados do século XIX, como podemos perceber na publicação de Francisco Adolfo Varnhagen, intitulada Memorial Orgânico que à consideração das assembleias geral e provinciais do Império apresenta um brasileiro, de 1850. Por intermédio desse documento, Varnhagen apresentou algumas medidas que teriam por finalidade homogeneizar a população brasileira dentro de um ou dois séculos, embasado nos argumentos de que o tráfico de africanos deveria acabar, pois "eles [os escravizados africanos] não dormem tanto como se pensa e já têm feito seus ensaios em vários anos". Assim, é fundamental, para não ver "os vossos netos reduzidos talvez à condição de servos dos netos africanos”, que, “desde já, nenhum navio possa levar um só a seu bordo" (VARnhAGEN, 1850, p.22).

A defesa da miscigenação e a busca pelo branqueamento do país significaram, segundo Guimarães (2001a), a institucionalização da desmemória das origens étnico-raciais. Ou seja, de um lado, a imagem de Portugal deveria ser afastada, pois lembrava a "subordinação" do Brasil com relação à antiga metrópole; de outro, a imagem "servil" da escravidão deveria ser apagada com o branqueamento da população, sendo que a criação sobre o indígena "primitivo" e "selvagem" deveria ser substituída, agora, pela imagem romantizada dos guerreiros. Isso significa que afro-brasileiros e indígenas são aceitos, não como pessoas, mas como "marcos da brasilidade” (Guimarães, 2001a, p.387). 
As teorias eugênicas, fortemente empregadas em toda a Europa para "combater a degeneração racial” estavam colocadas textualmente na legislação brasileira, como, por exemplo, no decreto $\mathrm{n}^{0}$ 528, de 28 de junho de 1890 , assinado pelo então presidente Marechal Deodoro da Fonseca, que regulamentava a entrada de imigrantes no Brasil, determinando que:

É inteiramente livre a entrada, nos portos da República, dos indivíduos válidos e aptos para o trabalho, que não se acharem sujeitos à ação criminal de seu país, excetuados os indígenas da Ásia ou da África, que somente mediante autorização do Congresso Nacional poderão ser admitidos de acordo com as condições que forem então estipuladas (BRASIL, 1890, art. 20)3.

\section{0 IDEAL DE EMBRANQUECIMENTO NO INÍCIO DO SÉCULO XX: REGULAÇÃO POPULACIONAL, EUGENIA E RACISMO INSTITUCIONAL}

As correntes teóricas que alegavam uma inferioridade física, moral e intelectual dos não-europeus também estavam presentes nos textos de Oliveira Viana, que defendeu a miscigenação como algo positivo, pois assim a população brasileira se embranqueceria. Viana, que escreveu seus trabalhos na década de 1920, argumentava, fundamentalmente, que a viabilidade política do Brasil estava na sua “arianização", por meio de uma imigração seletiva. Tratava-se, portanto, da verificação da miscigenação como um dado da sociedade brasileira e, a partir dela, trilhar um caminho para a eliminação ou, no mínimo, a redução significativa da presença negra.

João Baptista Lacerda, ex-diretor geral do Museu Nacional, é conhecido pela sua argumentação proferida durante o I Congresso Internacional das Raças, ocorrido em Londres, em 1911. Lacerda esteve, naquela ocasião, representando o então presidente da república brasileira, Hermes da Fonseca, e sua fala foi bastante esperada, pois os participantes do congresso viam o Brasil como um caso de sucesso a ser copiado, na busca de embranquecimento da população. Durante sua fala, Lacerda, representante do mais respeitado instituto de antropologia e história natural do Brasil, previa que dentro de cem anos o Brasil se tornaria um país completamente branco a partir da mistura entre brancos, afro-brasileiros e

3 O mecanismo de exclusão do decreto $\mathrm{n}^{0} 528$, de 28 de junho de 1890 , assinado por Marechal Deodoro da Fonseca, foi atualizado pelo decreto-lei no 7967 , de 1945, que vigorou até 1957 e que determinava que: "Atender-se-á, na admissão dos imigrantes, à necessidade de preservar e desenvolver, na composição étnica da população, as características mais convenientes da sua ascendência europeia” (BRASIL, 1945). 
indígenas. Ele chegou a dizer que os brasileiros deveriam deixar de ser preconceituosos quanto à população negra, e que deveriam considerar os casamentos inter-raciais como uma boa alternativa para o futuro da nação, único caminho para o embranquecimento populacional (LACERDA, 1911). Se ele estivesse vivo em 2011, ano do centenário de sua idealização racista, certamente se impressionaria com o resultado de sua previsão; ou, então, verificaria que o racismo no Brasil é tão grande que não possibilitou um aumento expressivo dos relacionamentos inter-raciais. De acordo com Rita Segato (2005, p.81), "a antiga prática da miscigenação que produzira a cor do Brasil ‘incluído’ dos nossos dias tornou-se estatisticamente irrelevante, para não dizer inexistente. Um processo de segregação crescente passou a tomar seu lugar e se instalou entre nós".

A eugenia se tornou princípio constitucional ao ser incluía na Constituição Federal Brasileira, de 1934, em seu artigo 138, com a seguinte redação: "Incumbe à União, aos Estados e aos Municípios nos termos das leis respectivas [...]: b) estimular a educação eugênica [...]; g) cuidar da higiene mental e incentivar a luta contra os venenos sociais”. Entre os constituintes, havia muitos médicos, entre eles Antônio Carlos Pacheco e Silva, que argumentava pela "melhoria racial", dizendo que: "Há um esforço continuado para se obterem melhores cavalos, suínos, caprinos, enquanto se recebem as correntes imigratórias sem uma seleção individual dos imigrantes, desprezando os mais elementares preceitos indispensáveis à defesa da raça" (VILLA, 2011, p.55). Um dos membros constituintes, Xavier Oliveira, defendeu a inclusão do assunto ao texto constitucional dizendo:

\begin{abstract}
De orientais poucos assimiláveis, bastam no Brasil os cinco milhões que somos, os nordestinos e planaltinos de Minas, Mato Grosso e Goiás, sem falar dos autóctones da Amazônia, os quais quatro séculos de civilização passaram indiferentes à sua inferioridade patenteada numa decadência incontestável, que marcha para uma extinção talvez não remota (VILLA, 2011, p.54-55).
\end{abstract}

Os anos 1930 inauguraram a incorporação subordinada e tutelada das massas urbanas, trazendo respostas às constantes reivindicações populares com a ampliação da legislação previdenciária e trabalhista ${ }^{4}$, concomitantemente a uma maior concentração das decisões nas mãos do Estado. A mesma incorpo-

4 A principal referência é a Lei de Amparo ao Trabalhador Brasileiro Nato, assinada por Getúlio Vargas, em 1931, que estabeleceu uma cota de dois terços dos empregos em estabelecimentos industriais, que deveria ser ocupada por brasileiros natos, considerando a grande população de imigrantes europeus que vivia no país através do estímulo do Estado brasileiro. 
ração subordinada se deu na arena política, através da propagação da ideologia da nacionalidade mestiça e do povo mestiço. De acordo com Silvério (2004), a miscigenação, que no final do século XIX e início do XX era vista como o grande malefício do país, passa a ser, a partir da década de 1930, a "tábua de salvação para a construção da nação". Em suas palavras, o mestiço é "alçado à condição de símbolo nacional representando tanto a 'harmonia racial' quanto a possibilidade de embranquecimento paulatino da nação" (SIlvério, 2004, p.41).

Os primeiros anos do século XX são especialmente importantes para compreendermos o desenvolvimento de discursos racistas que permaneceram durante todo o século, porém sempre com novas roupagens. Obras como Casa Grande \& Senzala (1933) e Sobrados e Mucambos (1936), ambas de Gilberto Freyre, são ainda hoje muito citadas, seja para apontar o ineditismo para a época na discussão sobre o regime escravista e as relações raciais no Brasil (fazendo frente ao discurso eugênico), seja para discutir sobre suas limitações ao romper, definitivamente, com o reducionismo biológico marcante da época, tal como aparece em Oliveira Vianna, Silvio Romero ou Nina Rodrigues.

O fato é que a obra freyreana sintetiza o desejo de afirmação da nação enquanto mestiça. O mestiço foi transformado em patrimônio imaterial do Brasil, "marca de brasilidade" que tem uma dupla função, tal qual uma carta curinga utilizada conforme a conveniência: por um lado, para aproximar e causar a ilusão de que somos harmoniosamente misturados; de outro, para demarcar muros e manter as distâncias sociais. Esta última função é perceptível, principalmente, quando os espaços sociais hierarquicamente estabelecidos passam a ser questionados; então, surgem falas do tipo: "somos misturados, não dá para saber quem é negro no Brasil, portanto, é impossível pensarmos em ações afirmativas” (MEdEIRos, 2009). O interessante é perceber que dificilmente observamos pessoas com dúvidas de quem é branco no país, sendo que o "problema" só aparece quando se fala em população negra. Essa incoerência é o que dá forma ao mito brasileiro da democracia racial e nos mostra o quão utilizado é o "curinga" do mestiço, no sentido da demarcação de muros e da pronta contestação contra medidas que visem modificar as estruturas hierárquicas ${ }^{5}$.

5 O racismo no Brasil se deu de forma articulada com o preconceito de gênero. O Plano Nacional de Educação, de 1937 (produzido na época de atuação do Ministro de Educação Gustavo Capanema), propõe um currículo de ensino médio específico para meninas de 12 a 18 anos, para prepará-las para a vida doméstica. Capanema idealizou o Estatuto da Família, que determinava em seus artigos 13 e 14 que "às mulheres será dada uma educação que as torne afeiçoadas ao casamento, desejosas da maternidade, competentes para a criação dos filhos e capazes da administração da casa [...]. Não poderão as mulheres ser admitidas senão aos empregos próprios da natureza feminina e dentro dos estritos limites da convivência familiar" (CosTA, 2008, p.249-250). No 
Um dilema de caráter político-social esteve posto no início do século XX: no pós-abolição e com a presença do imigrante europeu, quais seriam as possibilidades de transformação do escravizado em trabalhador livre, estendendo efetivamente os direitos de cidadania à totalidade da população? Dito de outra forma, qual a viabilidade de um novo projeto social, pautado agora em direitos, na livre associação e no trabalho assalariado? Gilberto Freyre, ao lançar luz sobre a temática racial em outros termos, valorizando o mestiço, transformou o "problema" ou o “obstáculo" à integração nacional em sua maior força. Nessa medida, Freyre, por meio de uma leitura sofisticada da realidade brasileira, inverteu a chave sobre a miscigenação, tornando-a um dado a ser positivado no país. Com isso, equacionou o problema do povo brasileiro em outro patamar. Atentemo-nos, no entanto, que esse arranjo significou ao longo do século XX a marginalização da população afro-brasileira e indígena, na medida em que o discurso da miscigenação passou a ser um dos principais argumentos de que seríamos uma democracia racial, sem preconceitos de qualquer espécie e sem privilégios.

Sales Jr. (2006) salienta que a cordialidade e a estigmatização da população afro-brasileira, como tecnologias políticas, não surgiram no Estado Novo. No entanto, é a partir da década de 1930 que a estigmatização e a cordialidade produziram, a partir de algumas adaptações, uma utilidade política e econômica, consolidando o sistema inaugurado pelo Estado Novo. Esses elementos do racismo brasileiro se infiltraram nos mecanismos políticos mais amplos e a cordialidade se transformou em "eticidade" nas relações de poder do país (SALES JR., 2006, p.254). O Estado, portanto, agiu movido por um papel ético-moral, associado a uma capacidade crescente de assimilação cultural, que se deu, especialmente, a partir do sistema educacional - o que nunca impediu, no entanto, que surgissem movimentos de resistência. De acordo com Dávila (2006, p.245), o Estado Novo inaugurou um período de maior visibilidade, de expansão e de consolidação do nacionalismo eugênico iniciado em décadas anteriores.

Enquanto construção discursiva, a nação é narrada através da literatura, dos hinos, dos mitos de origem, das narrativas heroicas e das lendas; portanto, não se apresenta apenas de maneira coercitiva. Esses elementos são constantemente repetidos, de modo que a "nação" adquira atemporalidade. É por esse esforço narrativo que Benedict Anderson (1983) caracteriza as nações enquanto "comunidades imaginadas”. Homi Bhabha (1990, p.1), por sua vez, destaca que a nação,

caso das mulheres afro-brasileiras, estudos recentes confirmam que elas formam o grupo social mais subalternizado - em comparação com homens brancos, mulheres brancas e homens afro-brasileiros -, sofrendo um acúmulo de discriminações, racial e de gênero (PAIXão et al., 2010). 
enquanto conjunto de significados, apenas pode se efetivar "nos olhos da mente", ou seja, não há nenhuma materialidade possível fora do nível discursivo. De acordo com Hall (2006, p.48), as identidades nacionais "não são coisas com as quais nós nascemos, mas são formadas e transformadas no interior da representação", compreendendo as representações, aqui, enquanto um conjunto de significados, que geram sentimento de pertença, identificação e lealdade, tais como os significados de "brasilidade", "inglesidade", entre tantas outras construções.

Dessa maneira, uma cultura nacional é composta não apenas por um conjunto de instituições políticas, econômicas e culturais, mas, sobretudo, por símbolos e representações. A cultura nacional é, por isso, um dispositivo discursivo, na medida em que as estórias, memórias, desejos e heranças moldam o significado de nação, “costurando”, assim, as diferenças em uma única identidade (HALL, 2006, p.50-51 e 62-65). Obviamente, toda essa engenharia de significados é tensionada ao observarmos as condições reais de existência das populações negras e brancas nos contextos colonizados, como o Brasil.

Maio e Grin (2013) argumentam que a primeira legislação contra o preconceito racial no Brasil, a Lei Afonso Arinos, de 1951 (Lei 1.390) ${ }^{6}$, que tornava o preconceito uma contravenção penal, também foi uma forma de buscar legitimar o mito da democracia racial. Afinal, um país que mereceria o título de "uma das maiores referências na liquidação do racismo" não poderia deixar de ter uma legislação que tornasse esse argumento a máxima da nação. Seria, portanto, de acordo com os autores, uma legislação sem diálogo com a realidade racista, pois teria meramente um papel moral, ou seja, de manutenção do mito de que seríamos uma democracia racial (MAIO \& GRIN, 2013, p.43-44). Afonso Arinos, autor do projeto de lei, afirmou que um dos motivadores da proposta era a discriminação racial sofrida por seu motorista, José Augusto. Reforçando a noção de que no Brasil não seríamos acostumados com a prática de discriminações raciais, o deputado federal afirma, no que diz respeito a José Augusto:

Certa vez procurou-me revoltado para dizer que o empregado espanhol de uma confeitaria de Copacabana barrou-lhe a porta, após ter admitido a entrada da mulher e dos filhos com a recomendação de que ficasse esperando pela família do lado de fora. Isto era demais, no Brasil, sobretudo considerando que os agentes da injustiça eram quase sempre gringos, ignorantes de nossas tradições e insensíveis aos nossos velhos hábitos de fratermidade racial (FRANCO, 1965, p.178, grifo nosso).

6 Lei 1.390, de 03/07/1951, que "inclui, entre outras contravenções penais, a prática de atos resultantes de preconceitos de raça ou de cor” (BRASIL, 1951). 
Para além dessa afirmação, que reforça o argumento de Maio e Grin de que a legislação teria, simplesmente, um apelo moral, o motivador da lei mais descrito na literatura é o caso de discriminação racial sofrido pela atriz estadunidense Katherine Durham, que foi impedida de se hospedar em um hotel de São Paulo. No entanto, há um conjunto de acontecimentos políticos nesse mesmo período, nacionais e transnacionais, que nos levam a crer que a lei respondia a interesses mais diversos7 . A priori, é de se causar estranhamento o fato de que uma lei contra o preconceito racial tenha sido proposta pelo deputado federal da UDN - União Democrática Nacional -, Afonso Arinos de Melo Franco, ultraconservador e antissemita declarado (que, inclusive, escreveu, na década de 1930, nos Protocolos do Sábio de Sião, uma publicação que perpetuava o mito de uma conspiração judaica mundial) e que no momento em que propunha a lei também difundia a ideia de que no Brasil haveria harmonia racial. De acordo com o próprio Afonso Arinos, a lei seria mais preventiva do que fundamentada no reconhecimento de que, aqui, haveria uma sociedade sem racismo. Em seu discurso, Arinos defende que seu projeto deveria ocupar o lugar:

[...] d[a] integração política do negro no nosso convívio e no nosso complexo social. [...] [Trata-se de] uma conquista coletiva; a fixação, pelo Congresso, de uma velha tradição brasileira de fraternidade moral. É esta realmente a verdade. Não fosse o povo brasileiro instintivamente infenso aos preconceitos de raça e a tramitação de uma lei como a minha teria provocado verdadeiras batalhas. Haja vista o exemplo norte-americano, onde há mais de um século as correntes avançadas do pensamento procuram diminuir a resistência obtusa contra a aplicação do preceito constitucional igualitário, que foi adotado depois da Abolição (FrANCO, 1965, p.182).

Os resultados imediatos dessa lei, de acordo com Maio e Grin, seriam a tentativa de silenciar o movimento negro e, também, retirar a pauta das mãos do poder executivo, pois, como afirmava Arinos, Getúlio Vargas (eleito presidente em 1950) estaria usando a pauta do preconceito racial para mobilizar sua política populista ${ }^{8}$

7 Neste momento do texto, limitamo-nos a trazer os discursos sobre o mito da democracia racial presentes entre os legisladores e outros políticos da época. Ainda neste capítulo, e em momento mais oportuno, voltaremos a bordar a Lei Afonso Arinos, do ponto de vista das interferências transnacionais para sua proposição e aprovação. Além disso, passaremos pelas ações do movimento negro que antecederam e influenciaram a lei, bem como às críticas colocadas tanto pela militância quanto por cientistas sociais da época.

8 A lei chegou a ser batizada, em um determinado período, de "Lei Getúlio Vargas". Afonso Arinos fez críticas públicas a isso, acusando Vargas de estar fazendo uso político e eleitoral da lei. Nessa 
(MaIo \& Grin, 2013, p.40-41). Gustavo Capanema, ex-Ministro da Educação e Saúde, e que na época da Lei 1.390 era presidente da Comissão de Constituição e Justiça da Câmara, fez um pronunciamento de apoio à lei, o que também, em um primeiro momento, causou estranhamento, sabendo-se das feições eugênicas do político. Em sua fala, ele defende a proposta de Afonso Arinos por meio de uma retórica preconceituosa e estereotipada sobre afro-brasileiros e indígenas:

Por que se nega ao preto o que se não recusa ao índio quando a cultura daquele é superior a este? Por que se exalta o indígena e se despreza o africano quando maiores são neste as riquezas do coração? Se cultural e sentimentalmente o preto está colocado acima do índio, por que nos havemos de comprazer com a convivência deste e nos orgulhar da sua ascendência enquanto voltamos as costas ao preto e consideramos uma injúria nos suporem nas veias algumas gotas de seu sangue? O preto, o índio e o português concorreram para a formação do nosso povo. [...] Temos que aceita-la com os seus ônus e com as suas vantagens, integralmente, sem possibilidade de renunciar a qualquer de suas parcelas. Biológica e historicamente, o negro é parte essencial do nosso povo. Seja um bem, seja um mal, seja uma coisa que nos orgulhe, seja uma coisa que nos deprima, é essa a realidade (Diário do Congresso NACIONAL, 24 de agosto de 1950, p.5740).

Andreas Hofbauer (2011) salienta que os legisladores brasileiros sempre evitaram definir direitos ou, ainda, restrições tendo por bases explícitas questões de raça ou cor. Os processos de exclusão sempre foram controlados por grupos de poder que tinham muita autonomia perante o Estado, sofrendo pouca ou nenhuma interferência dele. Seguidos pelo ideal de branqueamento, "o jogo de poder se desenrolou nos engenhos, nas plantações, nas minas e, posteriormente, em fábricas, empresas, escritórios" (HofBauer, 2011, p.93).

Ao falarmos em nação ou em civilização brasileira estamos nos referindo, portanto, a discursos; compreendê-los é algo importante para a explicação dos processos que tornaram o mestiço e o mito da democracia racial em aspectos da "brasilidade" e em fenômenos duradouros ao longo de quase todo o século XX. É importante, portanto, destacarmos a ressalva feita por Stuart Hall a respeito da completa anulação das particularidades culturais por intermédio da assim

época, a escritora Raquel de Queiroz saiu em defesa pública de Arinos, publicando seu apoio no jornal Diário de Notícias, em 15 de julho de 1951 (MAIO \& GRIN, 2013, p.37). Esses episódios nos indicam alguma disputa pela autoria da lei que estava sendo abordada como mais uma prova da fraternidade racial brasileira. 
chamada "identidade nacional". De acordo com o autor, essa ideia está sujeita à dúvida, pois a violenta conquista colonial não se dá através de uma simples e total lealdade, união ou identificação simbólica (HALL, 2006, p.59). Antes disso, todo o processo de colonização se dá em meio a muita resistência, o que no Brasil é facilmente exemplificado através do caso do Quilombo dos Palmares (cujos primeiros registros de sua existência remontam ao ano de 1597; o quilombo existiu até 1695 , momento em que foi destruído fisicamente pelas forças oficiais), da Revolta dos Malês (1835), da Revolta da Chibata (1910) e das lutas que originaram as cerca de 3 mil comunidades quilombolas existentes na atualidade, de acordo com estimativas do INCRA9.

\section{DO MESTIÇO AO AFRO-BRASILEIRO: OS DESLOCAMENTOS IDENTITÁRIOS}

O marco inicial das amplas denúncias de desigualdades raciais no Brasil, ou seja, do início de um movimento contestatório da suposta harmonia racial, está nos anos 1950. Nesse período, foi lançado um grande projeto, encomendado pela UNESCO, que surgiu com o intuito de apresentar o país ao mundo como um modelo a ser seguido, pois teria resolvido de forma tranquila a problemática racial. Ou seja, ele surgiu dentro do argumento da democracia racial. A pesquisa, que contou com os pesquisadores Roger Bastide, Florestan Fernandes, Costa Pinto entre outros, acabou frustrando suas expectativas iniciais ao ter comprovado o preconceito racial persistente no Brasil, apesar das frequentes descrições do país como "paraíso racial".

Em termos teórico-conceituais, percebe-se um deslocamento na passagem dos anos 1950 para os anos 1970/80. Inicialmente, havia uma abordagem sobre o "preconceito de cor", o estereótipo e o desvendamento do mito da democracia racial, pautas presentes especialmente nas contribuições de Florestan Fernandes e Roger Bastide, que consideravam o racismo um arcaísmo do passado, não condizente, portanto, com a nascente sociedade de classes. A partir dos anos 1970, percebemos o deslocamento nas interpretações sobre o dilema racial brasileiro, que passa a ser discutido, agora, através das continuidades e acirramentos do racismo. Carlos Hasenbalg (2005) demonstrou que o racismo, longe de ser um arcaísmo, estaria intimamente relacionado ao capitalismo que se desenvolve no Brasil, conferindo oportunidades de maneira desigual, diminuindo as possibilidades de mobilidade social ascendente da população negra e aprofundando ainda mais as hierarquias

9 Disponível em: <http://www.incra.gov.br>. Acessado em: 02 de dezembro de 2015. 
raciais. Com a aprovação da Constituição Federal de 1988, se deu início no país a um tratamento político-jurídico da temática da diversidade e da igualdade racial, o que, em conjunto com as denúncias de racismo e de desigualdade racial, foram importantes no rompimento com os discursos da "nação mestiça" e de democracia racial. Esse período histórico significou um processo de luta política pela ressignificação do lugar da África na formação social brasileira, na busca pela desracialização da experiência negra.

O resgate, por parte do Movimento Negro, da categoria raça enquanto ferramenta de luta antirracista se mostra um golpe nos pilares que davam sustentação ao discurso nacional. O questionamento da tradição racista, base de nossa formação social e política, necessariamente representou um ponto a mais aos valores republicanos ideais. O Movimento Negro atuou, nesse sentido, para que o Brasil, enquanto comunidade imaginada homogeneamente, concedesse lugar a uma comunidade que se imagina culturalmente diversa, com conflitos, mas atenta para que estes sejam assumidos e enfrentados com medidas específicas.

Com a Constituição Federal de 1988 houve, então, o reconhecimento oficial por parte do Estado Brasileiro da diversidade cultural (artigos 215 e 216). O debate demonstrou um avanço no enfrentamento do racismo no Brasil, até porque, antes da $\mathrm{CF} / 88$, o que existia no país era apenas uma legislação punitiva do preconceito racial, considerando-o simplesmente uma contravenção penal. A nova Constituição passou a considerar a prática do racimo um crime e reconheceu as heranças culturais das populações negra e indígena na formação do país. Consideramos esses os primeiros passos dados no país para que fosse possível, de fato, ruir a identidade nacional mestiça e as "verdades" do discurso nacional.

No entanto, entendemos que o combate ao racismo não é efetivo se o compreendermos apenas em termos de instituições sociais. Esse é um ponto que merece algumas considerações gerais, até porque se relaciona diretamente com a tese central que norteou este texto. Partimos do pressuposto de que ocorre, especialmente a partir da década de 1980, um deslocamento no discurso nacional, antes informado pela igualdade através da mestiçagem, e que a partir de então se mostra tencionado e desestabilizado. Esse deslocamento está, segundo nossa hipótese, diretamente relacionado com a categoria raça e com as ações afirmativas. Se esse deslocamento de fato tenha ocorrido, em que medida isso se deu?

Gilberto Freyre, em 1933, nos informou que seríamos, desde o início, uma sociedade híbrida. Híbrida, de acordo com Freyre, significava que o Brasil, entre todas as sociedades da América, seria aquela que: 
[...] constituiu mais harmoniosamente quanto às relações de raça: dentro de um ambiente de quase reciprocidade cultural que resultou no máximo aproveitamento dos valores e experiências dos povos atrasados pelo adiantado; no máximo da contemporização da cultura adventícia com a nativa, da do conquistador com a do conquistado (FREYRE, 2006, p.91).

Na obra Interpretação do Brasil (1947), Freyre compara o Brasil com outros países rumo à modernização, dizendo que:

[...] os brasileiros vêm conseguindo ainda maiores triunfos, aplicando essa capacidade à esfera cultural e social, na maior amplitude. Daí sua relativa democracia étnica: a ampla, embora não perfeita, oportunidade dada no Brasil a todos os homens, independente de raça ou de cor, para se afirmarem brasileiros plenos (FREYRE, 1947, p.43).

A sociedade híbrida em Freyre é aquela que teria tido a capacidade de operar uma síntese cultural não conflituosa; e é isso que teria permitido a permanência dos códigos sociais com o mínimo de rusgas. As marcas da sociabilidade brasileira seriam, portanto, a acomodação e a conciliação, que são resultados (em partes) da assimilação cultural, pelo conjunto da sociedade, de usos, costumes e valores de diferentes referências culturais. $O$ hibridismo cultural seria, nessa medida, a adaptação equilibrada dos diferentes aspectos das culturas portuguesa, africana e indígena.

Com sua interpretação sobre a marca híbrida brasileira, Gilberto Freyre lançou luz sobre a temática racial em outros termos, valorizando o mestiço e, com isso, retirando-o da situação de "obstáculo à integração nacional" para o patamar do maior motivo de orgulho do país. Freyre inverteu, assim, a chave sobre a miscigenação, tornando-a um valor a ser positivado no país. O dado interessante dessa inversão é que ele equacionou o problema do povo brasileiro em outro nível, em um momento em que estava em debate a questão de como incorporar os ex-escravizados na nova lógica do trabalho assalariado e da conquista de cidadania. No entanto, o resultado desse arranjo ao longo do século XX foi a marginalização da população afro-brasileira e indígena.

Freyre imaginou uma síntese cultural para o Brasil. Entendemos que a sociedade híbrida da explicação freyreana tem pouca semelhança com a noção de um espaço genuinamente heterogêneo e de negociação democrática agonística, ou seja, de um espaço de remodelação constante, sem solução final. A sociedade híbrida 
só pode ser um espaço democrático se não se fechar em torno de uma identidade conservadora, e se nela for privilegiada a presença e a articulação da différance. Nos termos colocados por Hall (2006), é essencial que uma sociedade multicultural permaneça um espaço heterogêneo e pluralístico, resistindo ao ímpeto de serem integrados por um processo de equivalência formal, tanto no sentido assimilacionista - como dita a concepção liberal de cidadania -, quanto do ponto de vista da radicalização das diferenças no sentido "do certo contra o errado", do "bem contra o mal" (HALL, 2006, p.83).

As realidades colonizadas criaram um grande desafio, que é a necessidade de se desracializar a experiência de grupos sociais de origem não-europeia. $\mathrm{O}$ desdobramento atual, tanto teoricamente quanto no campo das lutas sociais por políticas públicas, se dá através de uma perspectiva diaspórica dos processos de racialização, na busca de uma recriação das origens da população afro-brasileira para além da fronteira nacional, pois essa fronteira nos isolou na lógica da mestiçagem e apagou as referências étnicas.

Um caminho de análise possível é focar o debate em torno de como os discursos produzem sujeitos ideais para si; afinal, o mito da democracia racial criou o negro, o indígena e o branco ideais para a síntese nacional - ou para essa comunidade imaginada. Esse caminho analítico é interessante para compreendermos os resultados do processo colonial. No entanto, ele nos diz pouco quando buscamos explicações sobre a forma como se opera a subjetividade, ou a constituição subjetiva dos sujeitos, a imanência do ser negro ou africano, ou afro-brasileiro, por exemplo. Dessa maneira, ainda que o racismo brasileiro possa ser analisado a partir da análise das instituições sociais e da construção discursiva, é possível, também, aproveitarmos outros insights já tão bem expressos em autores como Frantz Fanon e Avtar Bhah, para citarmos apenas dois.

$\mathrm{O}$ discurso racial no Brasil, emoldurado pelo mito da democracia racial e que ganhou impulso no começo do século XX, transformou, em função de uma série de mutações simbólicas, o bantu em africano; o africano em escravo (sim, "escravo", como se assim o fosse desde sempre, como se não tivesse passado por um violento processo de escravização); o escravo em homem de cor; o homem de cor em mestiço; a mulher de cor em mulata; a mulata em puta. Dessa maneira, o que Fanon (2010, p.245) chamou de "racialização do pensamento" é também debatido por Avtar Brah (2006) no sentido de "diferença enquanto subjetividade", ou seja, buscar compreender como as representações sociais presentes nos discursos reverberam no campo subjetivo e nos constrangem a nos tornarmos e a nos sentirmos de determinadas maneiras. 
Fanon dialoga de dentro da mais profunda batalha entre a representação psíquica e a realidade social. O corpo negro, para Fanon, fende-se, de um lado, para uma dialética hegeliano-marxista; de outro, para uma afirmação fenomenológica do "Eu" e do "Outro", e, por último, para uma ambivalência psicanalítica do inconsciente (ВНАвна, 2010, p.71). Fanon explora, nesses termos, cada um desses polos de pensamento, devolvendo a esperança na história, evocando a completude do Eu, demandando a desracialização do marginalizado e iluminando, através da psicanálise, os jogos de prazer, medo, loucura, dor e poder do discurso colonial. Com isso, Fanon questiona radicalmente tanto a formação da autoridade individual como da social na modernidade, colocando em xeque as "virtudes sociais" da racionalidade histórica, da coesão cultural e da pretensa autonomia da consciência individual. Ao negro, de acordo com o filósofo, é negado o processo de humanização, na relação eu-outro e na criação de um "nós”. O autor questiona, assim, a validade do "pensamento racional", que construiu um espaço social de extrema violência, de imagens febris, delirantes e de ódio racial, em nome da "virtude cívica”. Quem é o racional, afinal?

\section{CONSIDERAÇÕES FINAIS}

Se a categoria raça, recolocada pelo Movimento Negro brasileiro, especialmente a partir da década de 1980, tem esse viés da reconstrução subjetiva do lugar da África e do africano no Brasil, não podemos mais ler o país para dentro de qualquer limite nacional ou para dentro do limite argumentativo da mestiçagem. No mesmo sentido, o Movimento Negro das últimas décadas não pode mais ser lido na chave de um movimento homogêneo e centrado em uma luta de "retorno à África" ou a uma origem intocada. Desse ponto de vista, Avtar Brah (2011, p.212) nos auxilia ao realizar uma distinção conceitual entre diáspora, no sentido teórico, e diáspora, no sentido de experiência. Frequentemente, podemos operar em uma concepção excessivamente simplista de pertencimento e nos fecharmos em novas formas de fechamento étnico. Deve-se ter em mente que etnicidade não significa uma comunidade, pois isso significaria recuperar a estratégia assimilacionista do iluminismo através de um longo desvio de percurso. Do ponto de vista dos negros brasileiros, a crítica diaspórica, no sentido de desvendar a experiência, traz uma perspectiva ampla sobre a dinâmica social, de modo a permitir observar as lógicas de perpetuação do racismo e o que significou historicamente ser "negro", ser "moreno" ou ser "mestiço". 
O negro no Brasil, por meio do movimento social, reafirma-se enquanto afro-brasileiro; e ele, ademais, tem trilhado o caminho de recriar sua origem para além da fronteira nacional, ou seja, não é um retorno ao lar africano, mas refazer sua subjetividade, em um terceiro espaço, um território subjetivo. Isso se dá através da crítica à racialização de sua pertença étnica e, ao mesmo tempo, da crítica à hierarquização a qual foi submetida sua história, denunciando a maneira como a diferença se transformou no Brasil em pretexto e justificativa para a desigualdade social e a exclusão. Aqui e na América Latina como um todo.

O caráter transnacional presente tanto no termo afro-brasileiro quanto na releitura diaspórica em si não significa se reportar à uma história cruzada entre África, Brasil e a todo o contexto da diáspora africana. Significa, por outro lado, realizar a crítica à fixação dos sujeitos realizada pelo discurso nacional. Afinal, há uma construção discursiva que nos constrange à posição de "brasileiros", quando, na verdade, somos tudo em nós mesmos, temos em nós muitas referências que nos impedem de nos fixarmos, a não ser provisoriamente. O afro-brasileiro, nessa medida, remete a um cosmopolitismo, um encontro de encontros (ou encontro de híbridos), mas sem universalismo e sem modernidade.

A III Conferência Mundial de Combate ao Racismo, Discriminação Racial, Xenofobia e Intolerância Correlata, realizada em Durban, na África do Sul, em setembro de 2001, constituiu-se uma grande arena onde temas importantes do circuito histórico e político do "Atlântico Negro" foram discutidos. O relatório brasileiro levado à Conferência listava um conjunto de propostas destinadas à promoção dos direitos da população negra; entre elas, estava a demanda por cotas ou outras medidas afirmativas que promovessem o acesso dos negros às universidades públicas. A partir daí, o assunto das ações afirmativas não parou de ganhar proporções nacionais, tanto em defesa quanto em crítica a elas. Mais do que isso, a Conferência de Durban pautou toda a década seguinte, pois elevou o debate sobre a questão racial a níveis nacionais, incentivando a produção e difusão de novos dados socioeconômicos, bem como de argumentos que fundamentavam a discriminação racial.

Do período de aprovação da Constituição Federal de 1988 até Durban, a estratégia de combate às desigualdades raciais no Brasil tinha continuado a trilha da proibição do preconceito e da punição de discriminações. Uma agenda mais propositiva e valorativa passou a surgir apenas no pós-Durban. Os compromissos firmados pelo Brasil durante a conferência colocaram, ao Estado brasileiro, a necessidade de demonstrar, no plano internacional, a disposição do país em cumpri-los e em fazer parte do grupo de países que adotam medidas de combate ao racismo. $\mathrm{O}$ 
debate em torno das políticas públicas para a população negra culmina, nos últimos anos, em desdobramentos teóricos interessantes, que passam pelo fortalecimento de medidas, tais como as Diretrizes Curriculares Nacionais para a Educação das Relações Étnico-Raciais e para o Ensino de História e Cultura Afro-Brasileira e Africana, bem como por uma ampliação do tema em termos transnacionais, algo evidenciado pelos esforços coletivos nos países da diáspora africana, com a participação de Núcleos de Estudos Afro-Brasileiros nas universidades (NEABs) e de organismos internacionais como a UNESCO.

Do ponto de vista de uma agenda política e de pesquisa sobre a questão racial brasileira, podemos dizer que vivenciamos um novo quadro, fundamentalmente atravessado por uma mudança normativa significativa e pela tensão da ideia de nação mestiça. A atual agenda nos traz um resultado interessante, que é o esgotamento da dicotomia negro versus branco, e a compreensão dos processos de racialização de um ponto de vista mais amplo, transnacional. O debate atual é, nesse sentido, o da reconfiguração da presença africana no Brasil, do reconhecer-se na história, ao mesmo tempo que a refunda.

Um dos reflexos do debate em torno das ações afirmativas no Brasil tem sido, então, o de suscitar esse novo espaço diaspórico de diálogo. Ele nos permite revisitar a própria Sociologia aqui realizada, desde Gilberto Freyre, passando por Florestan Fernandes, Carlos Hasenbalg e outros autores centrais do nosso meio. A adoção de políticas públicas específicas para a população negra não tem, em si, esse potencial reflexivo; mas a agenda transnacional, informada pelo conceito de diáspora africana, tem trazido como resultado alguns deslocamentos interessantes na produção intelectual brasileira, na própria formulação política e em como o Brasil se auto representa no cenário mundial.

\section{REFERÊNCIAS BIBLIOGRÁFICAS}

ANDERSON, Benedict. "As promessas do Estado-Nação para o início do século". In: HELLER, Agnes et al. A crise dos paradigmas em Ciências Sociais e os desafios para o século XXI. Rio de Janeiro: Contraponto, 1999.

AZEVEDO, Célia Maria Marinho de. Onda negra medo branco: o negro no imaginário das elites do século XIX. São Paulo: Annablume, 2004.

BHABHA, Homi K. O local da cultura. Belo Horizonte: Editora UFMG, 2010.

(Org.) Narrating the Nation. Londres: Routledge, 1990.

BRAH, Avtar. Cartografías de la Diáspora. Identidades en cuestión. Madrid: Traficantes de Suenõs, 2011. 
BRASIL. MINISTÉRIO DA EDUCAÇÃO. Plano Nacional de Implementação das Diretrizes Curriculares Nacionais para a Educação das Relações Étnico-Raciais e para o Ensino de História e Cultura Afro-Brasileira e Africana, Brasília: MEC/SEPPIR, 2009.

Diretrizes Curriculares Nacionais para a Educação das Relações ÉtnicoRaciais e o Ensino de História e Cultura Africana e Afro-Brasileira, Brasília: MEC/ SECAD, 2004.

BRASIL. MINISTÉRIO DA CULTURA. Conferência Mundial contra o Racismo, Discriminação Racial, Xenofobia e Intolerância Correlata. Declaração e Programa de Ação. Brasília: Fundação Cultural Palmares, 2001a.

BRASIL. MINISTÉRIO DA JUSTIÇA. Seminários Regionais Preparatórios para a Conferência Mundial contra o Racismo, Discriminação Racial, Xenofobia e Intolerância Correlata. Brasília: SEDH/MJ, 2001b.

BRASIL. CONGRESSO NACIONAL. Lei 1.39o, de o3 de julho de 1951. CN/PR, 1951. Decreto $\mathrm{n}^{0} 528$, de 28 de junho de $1890 . \mathrm{CN} / \mathrm{PR}, 1890$.

COSTA, Sérgio. Unidos e Iguais? Anti-racismo e solidariedade no Brasil contemporâneo. Novos Estudos do CEBRAP. Pensamiento Iberoamericano, $\mathrm{n}^{\circ} \mathrm{01}, 2008$.

DÁVILA, Jerry. Diploma de brancura: política social e racial no Brasil - 1917-1945. Tradução de Claudia Sant'Ana Martins. São Paulo: Editora Unesp, 2006.

DIÁRIO DO CONGRESSO NACIONAL, 24 de agosto de 1950.

FANON, Frantz. Os condenados da Terra. Juiz de Fora: Editora UFJF, 2010. Pele negra, máscaras brancas. Salvador: EDUFBA, 2008.

FRANCO, Afonso Arinos de Melo. A escalada. Rio de Janeiro: Editora José Olympio, 1965. FREYRE. Gilberto. Casa Grande \& Senzala: formação da família brasileira sob o regime da economia patriarcal. $51^{\mathrm{a}}$ ed. rev. - São Paulo: Global, 2006. . Interpretação do Brasil. Rio de Janeiro: Ed. José Olympio, 1947.

GUIMARÃES, Antônio Sérgio Alfredo. Classes, Raças e Democracia. São Paulo: Editora 34, 2002.

- "Nacionalidade e novas identidades raciais no Brasil: uma hipótese de trabalho”. In: SOUZA, Jessé de (Org.) Democracia hoje: novos desafios para a teoria democrática contemporânea. Brasília: Editora da UnB, 2001a.

."A questão racial na política brasileira: os últimos quinze anos”. Tempo Social. São Paulo, v. 13, n. 2, 2001b.

HALL, Stuart. Da diáspora. Identidades e mediações culturais. Belo Horizonte: Editora UFMG, 2006.

HASENBALG. Carlos. Discriminação e desigualdades raciais no Brasil. 2. Ed. Belo Horizonte: UFMG; Rio de Janeiro: IUPERJ, 2005. 
HOFBAUER, Andreas. Cultura, diferença e (des)igualdade. Contemporânea. Revista de Sociologia da UFSCar. $\mathrm{n}^{0}$ 01. São Carlos: 2011.

LACERDA, João Baptista. Sur les métis au Brésil. Congrès Universel des Races. Paris: Imprimerie Devouge, 1911.

MAIO, Marcos Chor; GRIN, Mônica. O antirracismo da ordem no pensamento de Afonso Arinos de Melo Franco. Revista Topoi. Vol. 14, n 26, jan./jul., p.33-45, 2013.

MEDEIROS, Priscila Martins. Raça e Estado Democrático: o Debate Sociojurídico acerca das Políticas de Ação Afirmativa no Brasil. Programa de Pós-Graduação em Sociologia, Universidade Federal de São Carlos, dissertação de mestrado, 2009. MISKOLCI, Richard. O desejo da nação: masculinidade e branquitude no Brasil de fins do XIX. São Paulo: Annablume, 2012.

MOYA, Thais dos Santos; SILVÉRIO, Valter Roberto. Ação afirmativa e raça no Brasil contemporâneo: um debate sobre a redefinição simbólica da nação. Sociedade e Cultura, Goiânia, v. 12, n. 2, p. 235-250, jul/dez. 2009.

MUNANGA, Kabengele; BIRCHAL, Telma S. Inexistência biológica versus a existência social de raças humanas: pode a ciência instruir o ethos social?. Revista da USP, n.68, p.10-21, 2006.

PAIXÃO, Marcelo; ROSSETO, Irene; MONTOVANELE, Fabiana; CARVANO, Luiz M. (Orgs.) Relatório anual das desigualdades raciais no Brasil: 2009-2010. Constituição cidadã, seguridade social e seus efeitos sobre as assimetrias de cor ou raça. LAESER - Laboratório de Análises Econômicas, Históricas, Sociais e Estatísticas das Relações Raciais. Rio de Janeiro: Garamond, 2010.

SALES JR., Ronaldo. Democracia racial: o não-dito racista. Tempo Social. Revista de Sociologia da USP. Vol. 18, n. 2, p.229-258, 2006.

SEGATO, Rita Laura. Cotas: Porque reagimos? Revista da USP. São Paulo, n. 68, p, 76-87, dez/fev 2005.

SILVÉRIO, Valter Roberto. "Negros em movimento: a construção da autonomia pela afirmação de direitos”. In: BERNARDINO, Joaze; GALDINO, Daniela (Orgs.) Levando a raça a sério: ação afirmativa e universidade. Rio de Janeiro: DP\&A, 2004.

VILLA, Marco Antônio. A história das constituições brasileiras. Duzentos anos de luta contra o arbítrio. São Paulo: Leya, 2011.

VARNHAGEN, Francisco Adolfo de. Memorial Orgânico. Instituto Histórico e Geográfico Brasileiro, código de referência: 44.2, 27. 1850.

Recebido para publicação em: 17/05/2015. Aceito para publicação em: 12/08/2015. 